\title{
AN AID TO CENTRAL VENOUS PRESSURE MEASUREMENTS*
}

\author{
L. A. Frostad, M.d. $\nmid$
}

ONE OF THE MOST DIFFICULT PROBLEMS in the continuous measurement of central venous pressure is that of maintaining a steady baseline for the water manometer when the position of the patient is changed. This applies equally to the patient in the operating room, where the table may be tilted from time to time in response to surgical requirements, and to the postoperative or other conscious patient who not only moves, but may actually be encouraged to move. Unless provision is made to maintain the zero point of the water manometer in constant relation to a fixed point on the patient and to effect frequent adjustments, serial readings of venous pressure may not be comparable and so give the erroneous impression of changes where none in fact exist.

To increase the reliability of readings, the standard venous pressure manometer should be complemented by the addition of some instrument which would ensure the constancy of the baseline. Many of the devices recommended in the past, such as carpenters' levels, transom scopes, right-angle squares, fall short of requirements because they do not assure that an identical point of reference on the patient is used every time the manometer is adjusted. We have designed an instrument which meets these requirements, and is simple to operate.

After consultation with our colleagues in the Anatomy Department we determined that the point on the body surface which is the most accurate fulcrum for position changes with the patient in the supine position is a point formed by bisecting a line dividing the A.P. diameter of the chest at its middle and anterior one-third by a line drawn vertically at the level of the third costal cartilage (Fig. 1). This point represents the zero level at the junction of the superior vena cava and the right atrium. Any change in position, except lateral placement, will not affect the zero level as long as that point is used as the rotational fulcrum.

In designing our instrument we kept in mind that (1) a liquid seeks its own level; (2) the level of liquid in a disc chamber does not change if the disc is rotated through one plane; (3) the atmospheric pressure at two ends of a water column can be kept reasonably constant with changes in volume and still be sealed water-tight if diaphragms are used to expand and contract and thus compensate for pressure changes. Based on these principles, the instrument we developed consists of a disc-like chamber filled with fluid to its centre mark and provided with a pressure diaphragm above the fluid level. This chamber is connected by rubber tubing to a glass column. The column also is fitted with a diaphragm to compensate for changes in air pressure (Fig. 2). The system is

\footnotetext{
'Presented at the Western Divisions Meeting, Canadian Anaesthetists' Society, March 29, 1968, at Vancouver, B.C.

†From the Department of 'Anaesthesia, University Hospital, Saskatoon, Saskatchewan. 501
}

Can. Anaes. Soc. J., vol. 15, no. 5, September 1968 


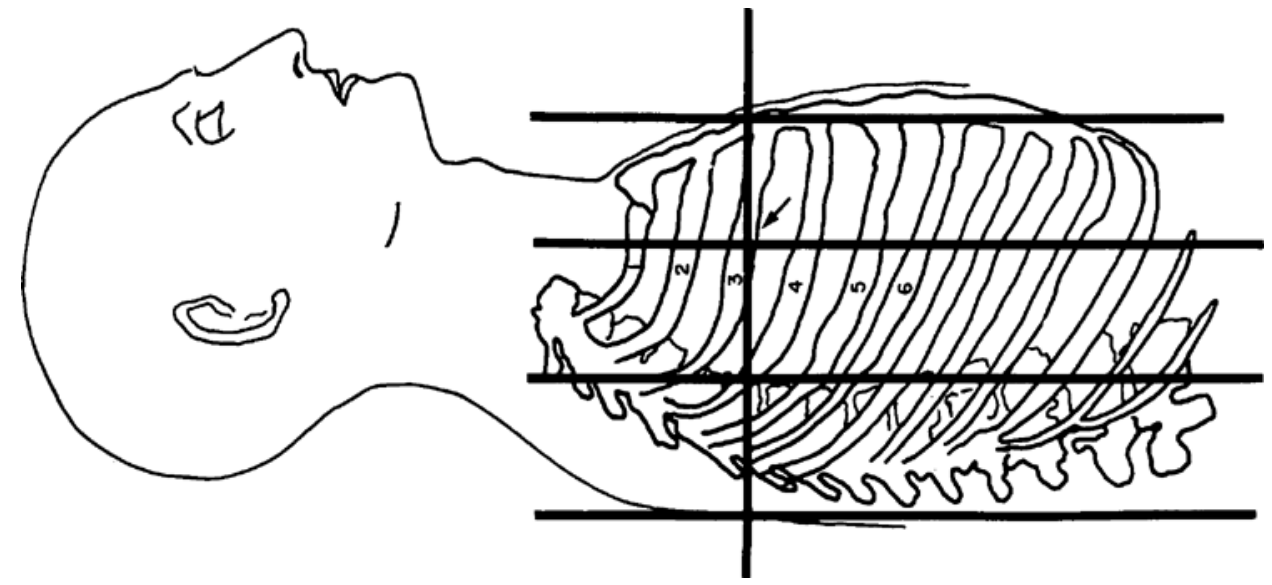

Frgune 1. The arrow indicates the site of attachment of the disc chamber to the thoracic wall.

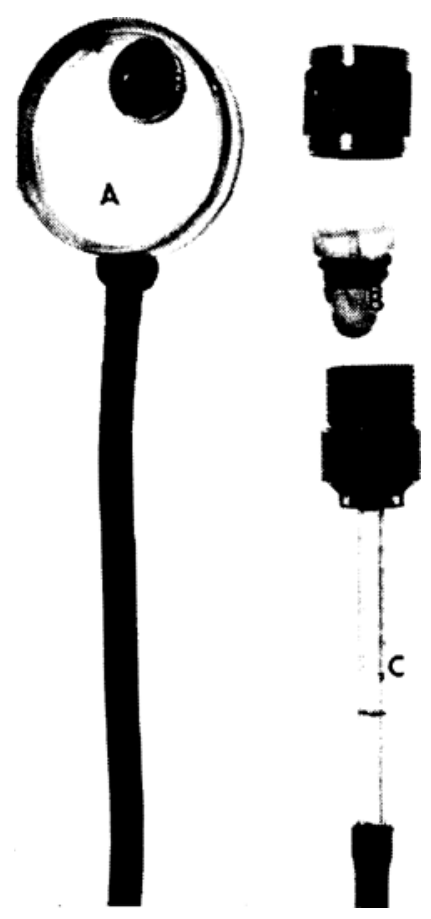

Figure 2. Apparatus disassembled. A-disc fluid chamber. $\mathrm{B}$-pressure compensating diaphragms. C-pipette fluid chamber. 


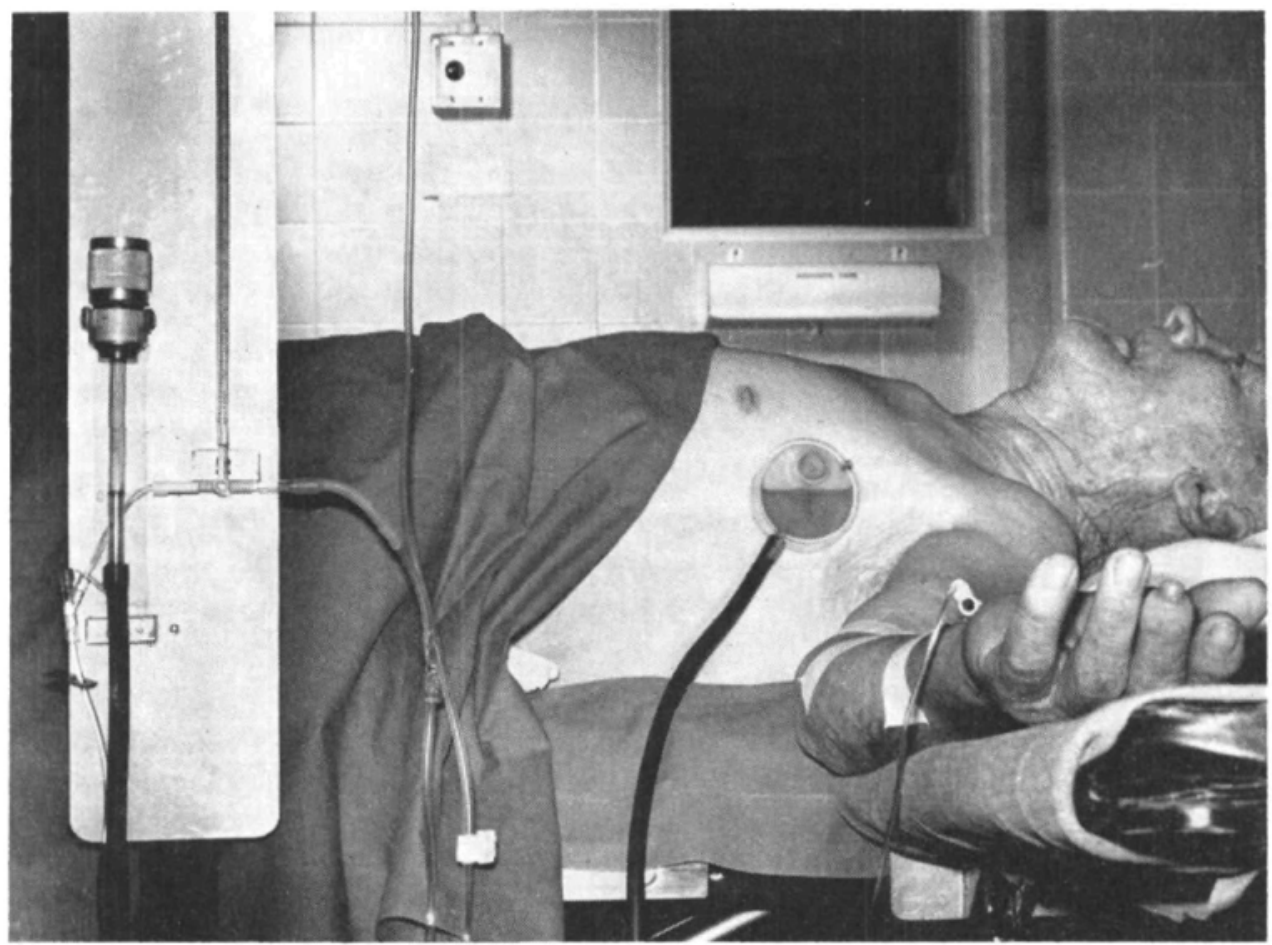

Figure 3. Apparatus assembled and in use with central venous pressure manometer attached.

flled with fluid through openings at each end which are sealed tight by a screwlike seal. The seal is applied when the fluid level in the disc and in the vertical chamber have been filled to a specified level, which is the centre point of the disc chamber and an arbitrary mark on the glass pipette. After the seal has been screwed into place the apparatus is leakproof, and any change in pressure inside the apparatus is compensated by expansion or contraction of the fine rubber diaphragms. The fluid remains at the exact level when the mark points are held side by side.

The disc-like chamber is now attached to the side of the chest wall at the predetermined site and the pipette chamber is mounted on a stand which can be raised and lowered simply by sliding it up and down an intravenous pole (Fig. 3). The fluid level in the pipette which has been set at the mark and has been equalized with the mid-point of the disc chamber is set opposite the zero level of the central venous pressure manometer.

It follows that whenever the fluid level in the pipette is at the ring mark, the fluid level in the disc chamber must be exactly at its centre. This principle allows us to ignore the patient completely in determining our zero level as long as he has not been rotated laterally. If the stand stays stationary and the patient's bed is raised, the fluid in the pipette will rise and the level in the disc will drop. Without the need to look at the patient, the attendant now knows that the pipette should be raised to bring the fluid level back again to the initial mark. 
Since pipette and manometer are mounted side-by-side this adjustment of the pipette must of necessity bring the zero-point of the manometer exactly level again with the surface marking of the right atrium.

Similarly, if rather than simply raising or lowering the bed, the patient is placed into the Trendelenburg or into a head-up position, the level in the pipette will change accordingly. But as the volume in the disc attached to the patient's chest is constant regardless of disc rotation, when the level is at the centre of the disc, it follows that again the mere raising or lowering of the stand to which pipette and manometer are attached will adjust the zero point, as long as the fluid level in the pipette is brought back to the mark.

Distance of the patient from the stand carrying the central venous pressure manometer and the zero level pipette is of no consequence, nor need the patient be in constant view, once the disc has been fastened securely to his chest. Therefore, during operation, the constant zero level can be maintained with ease even when the patient is completely draped, access is limited, and the anaesthetist must be some distance from the patient.

\section{SUMMARY}

A new device for location and maintenance of the zero level for central venous pressure determination has been presented. Even where the patient is hidden from direct view, changes in height or vertical rotation can be compensated by a change in height of the zero level fluid mark. The device is simple, leakproof, and harmless.

\section{RÉSUMÉ}

On présente un nouveau dispositif destiné à localiser et à maintenir le niveau zéro lorsqu'il s'agit de déterminer la pression veineuse centrale. Même lorsque la malade nous est caché, les changements en hauteur ou les changements de position peuvent être compensés par un déplacement en hauteur de la marque liquid du niveau zéro. Ce dispositif est simple, sans fuite et inoffensif. 